\title{
STUDENTS’ DECISIONS IN THE LOGISTIC SIMULATOR
}

\author{
Alexandra Gheondea-Eladi ${ }^{1}$, Ernesto Pacheco' ${ }^{2}$, Jaime A. Palma-Mendoza ${ }^{2}$, \\ Claudia Garay-Rondero ${ }^{2}$ and Ivan Arana-Solares ${ }^{2}$ \\ ${ }^{1}$ Research Institute for Quality of Life, Romanian Academy, Romania \\ ${ }^{2}$ Tecnologico de Monterrey, Ciudad de Mexico, Mexico
}

\begin{abstract}
This paper presents the preliminary results of a research on users decisions in a serious game, called Logistic Simulator or LOST. We provide an analysis of the first stage of an ethnographic decision tree modeling based on 20 interviews with students' who have used the simulator as part of their class assignment. Results show great variability in students' forecasting and production decisions, and more homogeneity in decisions related to suppliers and orders of raw material. The concluding section explains the impact of these preliminary findings and drafts further steps to develop this research.
\end{abstract}

\section{KEYWORDS}

Serious Games, Decision Tree Modeling, Ethnography, Educational Innovation, Higher Education

\section{INTRODUCTION}

In this paper we present a brief overview of preliminary results from an investigation of students' decisions in the business game LOST (E. A. Pacheco-Velazquez, Palma-Mendoza, \& Valdelamar-Dewar, 2020; E. Pacheco-Velazquez, Palma-Mendoza, Arana-Solares, \& Rivera, 2019). LOST is a serious game, designed for educational purposes in which students learn a range of logistics concepts in an intuitive and possibly more enjoyable way. Key performance indicators allow students to uncover the consequences and relevant variables of various logistics decisions. The game also creates a space for students to experiment and develop different kinds of strategies in order to win game profit.

The main question of this research is to understand how students make decisions in the Logistic Simulator (LOST). From an educational point of view, these decisions are expected to emerge in the form of decision-making rules, overall strategies and thinking patterns drawn from the simulator and which could be transferable to logistics and inventory management in real-life settings. To this aim an ethnographic decision tree modeling technique has been employed, with two parts: hypothesis building through ethnographic interviewing and hypothesis testing. In this paper we present the results from the first 20 interviews in the form of hypotheses related to how students make the relevant decisions in the game.

In short, we depart from a description of the methodology and go on to present the data analysis. In section 4, we present students' reported decisions and overall strategies from the LOST simulator.

\section{DECISIONS WITHIN THE LOST SIMULATOR}

Global markets, mass customization, reduced product life cycles and cost reduction are among the drivers behind an increased interest in logistics activities worldwide (Kherbach et al, 2016; Lee, 2016; Ballou, 1997). Hence teaching logistics concepts according to traditional teaching methods in logistics allows students to comprehend the concepts of an adequate operations management; however, through these methods, students lack the capabilities to put these concepts into practice (E. A. Pacheco-Velazquez, Palma-Mendoza, \& Valdelamar-Dewar, 2020). Faced with these challenges, serious business games focused on logistics offer a novel alternative that promotes the active participation of students (Cotter et al., 2009; Feng et al, 2008; Corsi et al, 2006; Sparling. 2002). Based on this objective, in recent years, professors in the logistics area of Tecnologico de Monterrey have created a business game called "LOST" (acronym for Logistic Simulator), The 
game simulates decisions made in the operation of a small supply chain. It mimics an enterprise dedicated to the production and sells of sports balls showing various degrees of difficulty captured in different versions of the game. From the start, the student is introduced to a quiz where relevant questions require answers based on the analysis of production and demand data. Depending on the number of correct answers, the player can start the game with a considerable amount of money or less, thus being forced to compromise more on the production line to meet demand. In the easiest version of the game, the one played by all students in this study, a sequence of decisions have to be made regarding the amount of product entering production, the type of suppliers to order from, how much raw material to order, and how much to transport to store. Key performance indicators, profit, cost and demand information are displayed for each game week to inform players about the outcomes of their decisions.

\subsection{Students' Journey in the Game}

The game consists of the simulation of a small supply chain. The company on which decisions will be made includes two facilities, a factory and a store. The game provides students with the history of demand for the last four years, and students must make a production plan that allows them to optimize the utility for this company based on the demand behaviour. Further information is provided regarding suppliers, product qualities, transportation and production costs.

Within the store 8 different types of balls are sold. Each one of them is produced through three different machines and uses three different types of raw materials. There is a limited capacity to use the machines (each machine can only work 80 hours a week), and this is the strongest production constraint that students are faced with. But in addition to this restriction, there are also restrictions on the amount of raw material that exists in the company's warehouse and the quality of the product.

On the other hand, there are also different suppliers of raw material. Suppliers differ in terms of: delivery time, quality of raw material, price per unit and shipping cost.

In carrying out the production plan of a single game round, students should visualize the inventory of each finished product from the store, obtain a forecast to determine what the sales will be, verify that the time of use of the machines does not exceed the 80 hours available, verify the existence of raw material available in the warehouse, and check if the restriction of the minimum quality that the products must have is met. Furthermore, students can use a decision support which allows them to visualize this information.

\section{METHODOLOGY}

Ethnographic decision tree modelling (EDTM) (Gladwin, 1989) is particularly helpful in studying both dichotomous decisions -- do or do not do - and more complex decisions. EDTM starts from a cyclical hypothesis building stage (1st stage), followed by a hypothesis testing phase (2nd stage) and ends with one or more decision tree model(s) (Gladwin, 1989). Although it emerged as a sociological method, it offers advantages for applications to information systems (Bailey \& Ngwenyama, 2014). In the hypothesis building phase ethnographic interviews are conducted in order to generate hypotheses regarding potential decision models. These may be comprised of (without exclusivity): the framing of the decision, potential decision attributes, their order and connections, decision tree shortcutting strategies, etc. In the second phase of EDTM the hypotheses formulated are tested on further samples from the same population.

In this report we present the results of the first stage of the EDTM, namely the analysis of qualitative interviews. Twenty participants who had played the LOST simulator as a class assignment in the spring semester of 2020 have been interviewed. The assignment was part of the course in supply chain management at the Tecnologico de Monterrey.

\subsection{Participants}

20 students were selected from classes taught by three different professors. Interviews were conducted in English by an external researcher. Professors were instructed to select for interviewing both students considered to have high and low proficiency as a result of classroom assessment. Students' confidence in answering questions in English has been a key factor influencing the total number of students participating in the interviews. Interviews were conducted online and audio- and video-recorded through Zoom. 


\subsection{Ethnographic Interviewing Technique}

The ethnographic interviewing technique is a type of unstructured interviewing in which the interviewer accumulates information from one interviewee to another. The questions are not fixed and they can vary greatly in the last interviews. There can be a core group of questions, but as interviewing progresses, the interviewer starts to add probing questions regarding the information which was provided in earlier interviews. In this case, the analysis becomes more complex, in the last interviews than in the first ones.

\subsection{Data Analysis}

A top-down content analysis of video-recorded interviews has been performed. Given that students have played one or two rounds in share screen mode, with the researcher, a transcription of the video recording has not been made, since this would deter the understanding and analysis of the material. The themes followed are related to the decision goals, strategies, criteria, emotions perceived, tricks and lessons learned. In the interviews, some of the students had improvement suggestions (Table 1). Based on the themes explored, hypotheses are formulated, such that in the second stage of the EDTM, these hypotheses can be tested. Interviews have been analysed in two stages: identification of themes and hypothesis formulation. In the results section, the hypotheses formulated will be provided. The data analysis will also identify: Overall strategies, Most relevant cues, Forecasting techniques and strategies, Tricks, Lessons learned, Suggestions to improve the game, Professor's goal framing, Personal purpose in the game, Information not used, Game goal, Source of previous information which could influence the game, the Goal when playing for the first time, the Goal when playing for the second time, etc. In the results section we will only present a selection of this information.

Table 1. Themes pursued in the content analysis

\begin{tabular}{l}
\hline Analysis type $\begin{array}{r}\text { Thecision goal(s) } \\
\text { Top-down }\end{array}$ \\
$\begin{array}{r}\text { Definition of the decision goal(s) } \\
\text { Strategy(ies) used to achieve the } \\
\text { goal(s) } \\
\text { Criteria perceived important for } \\
\text { achieving the goal(s) } \\
\text { Perceived Intermediary goals } \\
\text { Criteria perceived important for } \\
\text { achieving intermediary goals } \\
\text { Perceived success factors for } \\
\text { winning the game } \\
\text { (exogenous/endogenous) } \\
\text { Emotions perceived } \\
\text { Tricks } \\
\text { Lessons learned }\end{array}$ \\
Improvement suggestions \\
\hline
\end{tabular}

\section{RESULTS}

The goal of the first stage in EDTM is to formulate hypotheses regarding the decision rules, and cues which are used. In Table 2 we provide a short list of hypotheses which could be formulated after the data analysis. Some of these hypotheses are trivial, while others are not. The purpose of formulating them is to understand, in the second stage of the EDTM how many of the interviewees use these rules and how many do not. The decisions as they were structured by the game designers are different from the decisions that students make in the game. For this reason the analysis presented is structured according to students' decisions. 
Table 2. Hypotheses on students' decisions

\begin{tabular}{|c|}
\hline Hypotheses \\
\hline If maximum achievable quality has been achieved, produce more \\
\hline If maximum achievable quality has NOT been achieved, produce less \\
\hline $\begin{array}{l}\text { If supplier has higher quality, then order from it and order from second best quality to reach enough } \\
\text { quantity }\end{array}$ \\
\hline If quality is above $95 \%$, stop buying raw material \\
\hline If quality if below $95 \%$, buy more raw material \\
\hline If money is sufficient for production, buy more \\
\hline If money is NOT sufficient for production, buy less \\
\hline $\begin{array}{l}\text { If supplier of material A has highest quality and is also the most expensive or not, then order from it } \\
\text { If supplier of material A is the fastest to deliver, then order the rest of the amount left in stock from } \\
\text { this supplier }\end{array}$ \\
\hline If you win money in the quiz, order as much products and material needed to cover the demand \\
\hline If you do not win money in the quiz decrease amount produced to fit into cost \\
\hline Transport all products as soon as they are produced \\
\hline $\begin{array}{l}\text { If total amount produced doesn't fit in one transport; if small amount does not fit, subtract, if large } \\
\text { amount does not fit, transport anyway }\end{array}$ \\
\hline If total amount produced fits in one transport, then transport all \\
\hline If product has more demand in week 2 , then produce this product in the same amount \\
\hline If product has less demand in week 2 , produce the same now, but not next week \\
\hline $\begin{array}{l}\text { If there are NOT enough money to produce what you want, then order from cheaper suppliers, order } \\
\text { less raw material }\end{array}$ \\
\hline If demand for product $\mathrm{X}$ is high, then send to store half \\
\hline If your product sells, then produce more \\
\hline If your product does not sell, don't produce it anymore \\
\hline Forecast by average of half of all weeks for each products \\
\hline For the other half take maximum and minimums \\
\hline Compare these 2 points to the demand obtained in the previous week and see \\
\hline if demand in previous week is closer to that of the last week, then produce the highest number \\
\hline $\begin{array}{l}\text { After enough trials obtain } 3 \text { combinations of numbers which work best after trial and effort (to use all } \\
\text { the minutes of machines) }\end{array}$ \\
\hline If product does not sell then do not produce \\
\hline If transport can be filled with products then send \\
\hline If transport cannot be filled with products, do not send \\
\hline $\begin{array}{l}\text { If you DO NOT need to save money/profits then, if you are in last week, do not produce; and if you are } \\
\text { not in last week then produce (bad idea not to produce) }\end{array}$ \\
\hline Forecast demand as average of 100 weeks - not good \\
\hline Average of last 6 weeks better \\
\hline If there is already product in inventory, then produce less \\
\hline If there is no product in inventory, then produce exactly as forecasted \\
\hline $\begin{array}{l}\text { If product is cyclic then if product on low demand, then produce some more product to prepare for } \\
\text { high demand }\end{array}$ \\
\hline
\end{tabular}

Students' had to make 5 main decisions: which forecasting technique to use to approximate next weeks' demand, how much of each product to produce, from which raw material suppliers to order and how much to order from each. The decisions required making different kinds of trade-offs, in terms of product quality and quantity, time of delivery and price or quality of material and so on. Depending on the amount of money students' started with, they had to decide how to use the forecast or whether not to use it. In some cases, the expected demand could not be covered with available resources, and in this case some other decisions had to be made.

Two main observations can be made. First, there is a very wide variety of ways in which students have chosen to make the forecast, irrespective of their previous knowledge on forecasting techniques. More knowledgeable students have employed several forecasting techniques and averaged them or made tests to observe which of them comes closer to the actual data, while less knowledgeable students have relied on focal points (integer numbers, like 50,100) or made random guesses. Others have played the game many times and used combinatorial techniques to devise sequences of inputs which would lead to acceptable outcomes most 
often. Second, they all brought into the simulator personal beliefs which were not related to the rules of the game, like: products with higher quality will sell more than products with lower quality, one should order from all suppliers to distribute resources evenly in society and keep peoples' jobs and so on.

Some students played the game several times in order to determine 2-3 combinations of numbers which, once introduced in each week's production run would get them the highest profits, thus reducing the game to a combinatorial problem. Others decided to play the game more than once in order to improve their strategies, while others happened to play the game on several occasions as a result of previous courses or school events. Playing the game many times did not always lead to the best strategies, but students reported earning more money each time they played the game.

Also, strategies and decision rules varied much depending on whether students earned more or less initial money in the bank after answering correctly to a quiz. The learning process emerging after playing each full game made it fairly difficult to compare decisions of students who played it for the first time and those who played it several times. However, this will not be a limitation in the first stage of the EDTM, since the focus is not on building the general decision tree, yet, but on generating hypotheses regarding the cues students' employed.

\subsection{Decision 1: Forecasting}

Students reported using a wide variety of heuristics and rules for forecasting. The variability for this decision has been tremendous, with no two students using the same heuristic or rule. Reports differed sometimes based on the week number of the game, with use of more random strategies in the first 5 to 10 weeks, systematic decisions among weeks 5-20 and specific end of game strategies for the last 5 weeks of the game. Forecasting heuristics ranged from: using as forecast data the demand from the last 100 weeks of each product, corroborating the demand value from previous week with demand trend to decide whether to produce more or less than last week, using complex forecasting techniques taught during other courses, to making a correspondence between previous demand weeks and game weeks.

\subsection{Decision 2: How Much to Produce?}

Once the forecasting was done, students established ground rules in order to decide how much to produce. Students' use of the numbers emerging as a result of the forecasting showed great variation. Some students used the exact numbers obtained to determine how much to produce, given the inventory, while others rounded the figures or systematically produced more than the the forecasted number. For example, if forecasting value is $\mathrm{X}$, then some produced a little bit more than that number, minus the inventory. Two students have computer prediction errors. Other decision rules were: if the trend is stable, then produce the same amount as previous week's demand, or if the trend is downwards, then don't produce before you sell. Some students used all the data in the demand charts, for 100 weeks, while others focused on the last 50 or 5 weeks, with some reporting using only the demand data from last week or not using the demand data at all. Other students reported marking the weeks with maximum and minimum sales of each product in advance, in order to prepare production for those weeks. A few students reported focusing on the production of the products which had highest overall demand, producing only these products and fully neglecting the production of the least selling products.

When no forecasting was performed students' used several rules like: making sure they don't run out of any product, produce equal numbers of each product or introduce random numbers, produce more of those whose last week demand was higher and less of the others. Some interesting rules were based on the assumption that there will always be some kind of demand. Rules based on this assumption were: to have enough product in inventory such that increases in demand won't affect the profit; one can always cover low points in demand, so the focus should be on covering highs in demand; produce a lot of each product to prepare for weeks with high demand.

\subsection{Decision 3: Which Supplier to Order From?}

Overall strategies for deciding which supplier to order from ranged from ordering from all suppliers to choosing one or two suppliers for each raw material or one or two for only certain raw materials. Other students discarded suppliers which take 3 weeks to arrive, while others made sure to order a lot from these suppliers from the very beginning to make sure they always have a stock from this material. Many of those interviewed focused on 
price and time of arrival, while others focused on quality and time of arrival or took into consideration price only when the price difference was big enough. One student motivated ordering from all suppliers through the idea that people working in these companies should have work. Although this type of thinking indicates a personal interest in social aspects of life, this restriction was not included in the game. Another student valued suppliers' who raw material had higher quality than others. Such out of game thinking, but real-life relevant cues indicate the use of value-based, extended-rational decisions rather than strictly rational decisions (Opp, 1999).

\subsection{Decision 4: How Much Raw Material to Order?}

Overall strategies for deciding how much raw material to order ranged from systematically ordering raw material every week in the first weeks of the game to avoid increased shipping costs, to not ordering every week or focusing on ordering all the material that takes 3 weeks to arrive. Other students ordered random amounts of raw material, while others set their goal not to run out of raw material at any point. As before, the strategies employed for the raw material decision varied depending on how much monetary capital was available. Some ordered enough raw material to last them for the next week, while others ordered as much as possible to last them for more weeks.

\subsection{Decision 5: How Much Raw Material to use From Each Supplier?}

The decision on how much raw material to use in the production from each supplier was often mistaken for the decision to order material from each supplier. This may have been due to the fact that the interviews took place several weeks after students' had played the game or because this is how they played. Playing one game round or two with the researcher is likely to have shed this recollection problem. However, even under these circumstances, some students systematically confused the stage in which they decide how much raw material to use from stock with the stage in which they decide how much raw material to order. Some of these errors may have been due to the use of a second language than the native language, but this should be unlikely since the games' language was also English. Therefore, often times, when describing the decision to order raw material from each supplier, students were actually inputting data and using cues available for the decision on how much raw material to use from each supplier. This will impact the analysis of this decision.

\subsection{Decision 6: Transport Decisions}

Transport decisions exhibited, by nature, less variation than the other decisions. Students either decided to send all production to store irrespective of costs, to send most production to store as long as the second truck was not too empty or to always keep some inventory in the factory to have something to sell in the next week.

\section{CONCLUSIONS}

Students' decisions as presented in the previous section have not exhibited theoretical saturation with respect to forecasting methods and the choice of how much of each product to produce, in that no repetitive information has been observed between subjects for these two decisions. However, repetitive information has been observed for decisions related to the choice of suppliers, raw material and transport. It is expected that further information will be gathered on this topic in the second stage of the research.

In the second stage, a questionnaire will be built. The core part of the questionnaire will be structured in 3 sections: (1) main decisions made by students, e.g. forecasting, production, inventory use, suppliers, raw material and transport; (2) overall strategies; (3) lessons learned; (4) suggested improvements. Students' answers from the interviews will inform the phrasing of the items to be evaluated in each section. At the end of this endeavor researchers will have a clear view over students' decisions and suggested improvements, and will also be able to formulate actionable improvements for the learning process involved in the Logistic Simulator. 


\section{ACKNOWLEDGEMENT}

The authors would like to acknowledge the financial and the technical support of Writing Lab, TecLabs, Tecnologico de Monterrey in the production of this work. The authors would like to acknowledge the financial support of Novus Grant with PEP no. PHHT032-19ZZ00010, TecLabs, Tecnologico de Monterrey, in the production of this work.

\section{REFERENCES}

Bailey, A., \& Ngwenyama, O. (2014). Ethnographic Decision Tree Modeling: An Exploration of Telecentre Usage in the Human Development Context. In K.-M. Osey-Bryson \& O. Ngwenyama (Eds.), Advances in Research Methods for Information Systems Research. Data Mining, Data Envelopment Analysis, Value Focused Thinking (Integrated, pp. 63-78). New York: Springer.

Ballou, R. (1997). Business logistics: importance and some research opportunities. Gestão \& Produção. 4. 117-129.

Cotter, J., Forster, J. \& Sweeney, E. 2009. Supply Chain Learning - The Role of Games. Supply Chain Perspectives, the Journal of the National Institute for Transport and Logistics, Vol. 10, No. 3.

Corsi, T. M., Boyson, S., (2006), "The Real-Time Global Supply Chain Game: New Educational Tool for Developing Supply Chain Management Professionals," Transportation Journal, Vol. 45 (3), 61-73.

Feng, K.; Guohua, M. (2008). Learning Supply Chain Management with Fun: An Online Simulation Game Approach. California Journal of Operations Management. 6.

Gladwin, C. (1989). Ethnographic Decision Tree Modeling. In Ethnographic decision tree modeling (Qualitativ, pp. 9-67). Thousand Oaks, CA: SAGE Publica

Kherbach, O.; Mocan, M. (2016). The importance of logistics and supply chain management in the enhancement of Romanian SMEs. Procedia-Social \&Behavioral Sciences, 221, 405-413.

Lee, H. Y., Seo, Y. J., \& Dinwoodie, J. (2016). Supply chain integration and logistics performance: the role of supply chain dynamism. The International Journal of Logistics Management, 27(3), 668-685.Bailey, A., \& Ngwenyama, O. (2014). Ethnographic Decision Tree Modeling: An Exploration of Telecentre Usage in the Human Development Context. In K.-M. Osey-Bryson \& O. Ngwenyama (Eds.), Advances in Research Methods for Information Systems Research. Data Mining, Data Envelopment Analysis, Value Focused Thinking (Integrated, pp. 63-78). New York: Springer.

Opp, K.-D. (1999). Contending conceptions of the theory of rational action. Journal of Theoretical Politics 1, 11(2), 171-202.

Pacheco-Velazquez, E. A., Palma-Mendoza, J. A., \& Valdelamar-Dewar, D. A. (2020). Learning Skills Development Through the Usage of Simulators. In International Conference on Information Technologies in Engineering Education.

Pacheco-Velazquez, E., Palma-Mendoza, J., Arana-Solares, I., \& Rivera, T. C. (2019). LOST: A Serious Game to Develop a Comprehensive Vision of Logistics. In European Conference on Games Based Learning.

Sparling, D. (2002), "Simulations and Supply Chains: Strategies for Teaching Supply Chain Management," Supply Chain Management: An International Journal, Vol. 7 (5), 334-342. 